\title{
El concepto de reparación colectiva en el marco de la justicia transicional
}

\author{
The concept of collective reparation in the framework \\ of transitional justice
}

\begin{abstract}
RESUMEN
El concepto de reparación colectiva nace de la necesidad de ofrecer respuesta de reparación a grupos de poblaciones en determinados países, por la identificación de violaciones masivas de derechos humanos que los han afectado y que se han producido en contextos de violencia generalizada y sistemática, acusa de conflictos armados o graves alteraciones del orden público.

Estas necesidades reparativas se producen luego de la cesación de estos hechos y se pretenden satisfacer con la implementación de un marco de justicia que permita la transición hacia la paz. El presente trabajo analiza el tema de la reparación colectiva, la evolución y desarrollo del concepto y sus alcances, visibilizándose sus complejidades y limitaciones de cara a ofrecer una propuesta conceptual que integre todos sus elementos.
\end{abstract}

\section{PALABRAS CLAVE}

Reparación colectiva, Víctimas justicia transicional, Derechos colectivos, Daños colectivos.

\begin{abstract}
The concept of collective reparation arises from the need to provide compensations to population groups in certain countries for the identification of massive human rights violations that have affected them and which have occurred in contexts of generalized and systematic violence, armed conflicts or serious disturbances of public order.

These reparative needs occur after the cessation of these events and are intended to be met with the implementation of a framework of justice that allows the transition to peace. This paper analyzes the issue of collective reparation, the evolution and development of the concept and its scope, visualizing its complexities and limitations in order to offer a conceptual proposal that integrates all its elements.
\end{abstract}

\section{KEYWORDS}

Collective reparation, Transitional justice victims, Collective rights, Collective damages.

\section{MARY CRUZ ORTEGA HERNÁNDEZ}

Abogada. Magíster en Derechos Humanos, Interculturalidad y Desarrollo. Consultora en Derechos Humanos. Miembro del Grupo de Investigación Conflicto y Sociedad de la Universidad de Cartagena, Categoría A Colciencias.

temenanqui@hotmail.com

RAFAELA SAYAS CONTRERAS

Abogada. Docente Investigadora de la Universidad de Cartagena. Directora del Grupo de Investigación Conflicto y Sociedad de la Universidad de Cartagena. Magíster en Derecho de la Universidad Nacional de Colombia. Ph.D. en Sociología de la Universidad de Belgrano, Argentina. Docente en grado y posgrado. rasayas@ucm.es 


\section{INTRODUCCIÓN}

La teoría jurídica tradicional ha establecido reglas para las reparaciones por daños ocasionados a causa de injustos sufridos, históricamente estas reglas han tenido mayor impacto en lo relacionado con el Derecho Penal y el Derecho Administrativo, dentro de la división clásica de las ramas del Derecho.

Con el desarrollo del discurso de derechos humanos y sus mecanismos de protección se extiende el concepto de reparación que maneja la teoría jurídica tradicional al campo de las violaciones de derechos humanos e infracciones al Derecho Internacional Humanitario, es así como encontramos instrumentos de carácter internacional que establecen reglas y principios de reparación.

Desde este punto de vista de lo colectivo este concepto no había tenido mayores desarrollos, sin embargo las realidades de países que se encuentran o se han encontrado en situación de masiva y sistemática violación de derechos humanos, cualquiera sea la causa que la produce, ha demostrado que existen bienes que sufren daños por injustos que afectan no ya a los individuos por separado sino a los grupos y comunidades a los que estos pertenecen y que estos grupos y I. Justicia transicional: concepto y elemencomunidades son en sí mismos un ente dife- tos rente a la suma de sus individuos, que sufre daños por su carácter de tal.

Frente a estas realidades la teoría tradicional en materia de reparaciones se queda corta, por lo que se han tenido que establecer nue- vos esquemas y la respuesta se da en la propuesta de medidas de reparación colectivas, asociadas por lo general a planes nacionales de reparaciones de países que han salido de conflictos armados y se encuentran en el marco de lo que se ha venido denominando como justicia transicional.

En este trabajo de investigación revisaré los esquemas que a nivel internacional se han desarrollado en cuanto al concepto de reparación colectiva, sus alcances y limitaciones finalizando

\section{METODOLOGÍA}

La presente es una investigación jurídica de carácter cualitativo que ha sido abordad desde el análisis documental, que se divide en tres partes, inicia con la identificación del concepto de justicia transicional para visibilizar la base sobre la cual se asienta e Derecho a la reparación colectiva, continúa con los principales elementos teóricos con los que ha sido abordada la reparación coectiva, para finalizar con una propuesta de conceptualización de la misma que pretend integrar todos los elementos en una definición compleja.

El concepto de justicia transicional emerge a finales de los años 80 como respuesta a los cambios políticos experimentados en América Latina y Europa Oriental, y surge con la finalidad de hacer frente a los abusos come- tidos en los regímenes autoritarios que se experimentaron en estas zonas, compatibilizándolos con las transformaciones democráticas que allí se estaban asentado. Los nuevos gobiernos empiezan a implementar medidas tales como: Comisiones de la Verdad, Programas de reparación, acciones penales $y$ diferentes reformas institucionales.

“En primer lugar, atendiendo a que la justicia transicional puede anticipadamente definirse en términos muy simples como el conjunto de decisiones y mecanismos destinados a impartir justicia en asociación con un proceso de cambio político, se ha de advertir que su desarrollo tien como objetivo prioritario ofrecer soluciones adecuadas a la realdad social en tránsito para exigir responsabilidades $y$ ofrecer una reparación justa a las víctimas, respecto a los abusos a gran escala perpetrados durante un previo conflicto armado -incluyendo el contexto sociopolítico en el que el mismo se produjo-, com consecuencia de la represión ejercida po el régimen cuya extinción y substitución se pretende o ya se ha efectuado, o bien fruto de la dinámica de acción/represión presente en un Estado democrático en el cual las tensiones internas o la presencia de grupos terroristas comportaron en el pasado la presencia de un nivel intenso de violencia y de inestabilidad política e institucional" (...)

"En segundo lugar, la justicia transiciona es, en si misma, un proceso que se rrolla a lo largo de un periodo de tiempo más o menos prolongado: es, pues, un proceso dentro de otro proceso $-\mathrm{el}$ de transición política-; de este modo, las exigencias políticas condicionan tanto las decisiones y mecanismos de justica transicional que se adoptan como su funcionamiento real y efectivo, pero, lógicamente, la política de justicia transicional seguida es un factor que influye también en el propio desarrollo del proceso de cambio político" (Bonet Pérez, Alija Fernández, 2009, p.12).

Encontramos entonces que la justicia transicional presenta dos dimensiones: una de carácter judicial que privilegia la investigación de los hechos ocurridos y la imputación de responsabilidades a los perpetradores y una dimensión política que integra una serie de procesos que conducen a la transformación social e institucional de los Estados.

De acuerdo con el ICTJ, la justicia transicional se configura como:

"Una respuesta a las violaciones sistemáticas o generalizadas a los derechos humanos. Su objetivo es reconocer a las víctimas y promover iniciativas de paz, reconciliación y democracia. La justicia transicional no es una forma especial de justicia, sino una justicia adaptada a sociedades que se transforman a sí mismas después de un periodo de violación generalizada de los derechos humanos" (Centro Internacional para la Justicia Transicional, 2009).

La justicia transaccional se presenta como 
un momento político de sociedades que pretenden salir de periodos dictatoriales o de conflictos y tensiones, lo que implica una salida negociada de esas situaciones entre los distintos actores involucrados, "de este modo el conflicto se resuelve por medio de la transacción, en un doble sentido, pues no solo se busca materializar un pacto para poner fin a las diferencias entre las partes implicadas, sino que, además, para llegar a dicho acuerdo las partes deben transigir, es decir, consentir en parte con aspectos que no se consideran justos o razonables" (Bonet Pérez, Alija Fernández, 2009, p.137), por lo que necesariamente se tendrá que hacer un balance para lograr un equilibrio entre las aspiraciones de paz y las de justicia.

Por lo tanto, la justicia transicional trata de adaptar los esquemas jurídicos tradicionales y ordinarios a situaciones excepcionales, con la finalidad concreta de alcanzar la paz, la estabilidad política y la consolidación de la democracia, a través de diversos mecanismos que implican tensiones entre las aspiraciones de los involucrados. Estos mecanismos se concentran principalmente en cuatro grandes áreas:

a) La investigación de los hechos de violaciones de derechos humanos ocurridos durante los periodos de violencia, destinados a la construcción de lo que ha dado en llamar memoria histórica, entendido como un proceso participativo en el que los directamente involucrados narran lo sucedido y el Estado tiene el deber de promover esas narraciones, conservar dicha memoria colectiva y dar a conocer lo sucedido. Esto se enlaza directamente con el derecho a la verdad, como un derecho individual y colectivo.

b) La persecución y sanción, implica el establecimiento de instrumentos jurídicos alternativos para la judicialización y castigo de los perpetradores de violación de derechos humanos, casi siempre estos instrumentos son el resultado de la negociación entre los actores de los conflictos para permitir el establecimiento de privilegios en la aplicación de las sanciones a cambio de la dejación de las armas. Este elemento se relaciona con el derecho a la justicia.

c) La reparación, implica la aplicación de diversos mecanismos y herramientas tanto judiciales como administrativas, para satisfacción de los derechos a la restitución, indemnización, satisfacción y rehabilitación de las víctimas individuales y colectivas. Este elemento se relaciona con el derecho a la reparación integral.

d) Por último, la prevención, que implic entre otras cosas, la transformación de todas las instituciones y situaciones estructurales que dieron origen al conflicto, con la finalidad de que los hechos violentos no se vuelvan a repetir. Este elemento está relacionado con las garantías de no repetición.

Como vemos en un marco de justicia transicional se debe asegurar el cumplimiento de los derechos a la verdad, la justicia, la reparación y las garantías de no repetición. En este sentido se expresa Brito Ruiz al tratar de presentar un modelo de justicia transicional con enfoque restaurativo:
"Un proceso de justicia transicional que pretenda ser restaurativo deberá tener cuatro niveles: un primer nivel, que tiene que ver con el derecho a la verdad de las víctimas y está materializado en las com siones de verdad y sus informes de memoria histórica. Un segundo nivel, que tien que ver con el derecho a la justicia y que debe comprender desarrollos jurídicos que y que la forma como se lleven los casos sea transparente y ejemplarizante para la sociedad. Un tercer nivel, relacionado con el derecho a la reparación. Que se expresa en programas de reparación material simbólica. Y un cuanto nivel, enfocado en la garantía de no repetición, que implica cambios en las bases culturales y estructurales de la sociedad y el Estado (políticas públicas)" (Brito Ruiz, 2010, pp.71 y 72).

Por lo tanto, la justicia transicional se conforma como un proceso jurídico y político en el que el que se pretenden lograr a través de diversos mecanismos e instrumentos excepcionales, la transformación de las estructuras sociopolíticas que fueron causa de conflictos y tensiones y que se presenta como respuesta a las graves, masivas y sistemáticas violaciones de derechos humanos para la que los procesos y normas ordinarias tanto nacionales como internacionales no tienen respuestas adecuadas.

Es, en el marco de estos procesos en lo que se produce la necesidad debido a la magnitud de los daños experimentados de esta-

blecer mecanismos que tiendan a satisfacer Pasamos a revisar los elementos internos, los derechos a la indemnización, restitución, rehabilitación, satisfacción, y garantías de no repetición para los grupos, comunidades y la sociedad misma que se han visto afectados como consecuencia de la magnitud y masificación de las violaciones; esto es desarrollar herramientas para las reparaciones colectivas.

II. Elementos teóricos de la reparación colectiva

La reparación colectiva es una forma de reparación que se produce como consecuencia de hechos masivos y sistemáticos de violaciones de derechos humanos y está dirigida no a individuos sino a grupos de personas afectados. Se produce con independencia de las reparaciones individuales que se establezcan. Esta forma específica de reparación tiene su sustento en un marco jurídico especial como es el de justicia transicional, por la identificación en este marco de graves violaciones que afectan a grupos y colectivos en su carácter de tal para las cuales no existian respuestas. De allí que en la actualidad se esté debatiendo fuertemente el concepto y los elementos de este tipo de reparación, basándose en gran medida en la experiencia de países que lo han intentado aplicar. La reparación colectiva es, por tanto, un concepto en construcción. De acuerdo con nuestra investigación podemos proponer tres dimensiones externas del concepto de reparaciones colectivas: la jurídica, la política y la contextual, como sigue. 
que a nivel doctrinal conforman la reparación colectiva:

"El término <<reparaciones colectivas > es ambiguo, la palabra <<colectivas $>$ se usa para calificar, por una parte, $<<$ las reparaciones $\gg>$, es decir, los tipos de biene distribuidos o modo de distribuirlos y, por otra, el <<sujeto»> que las recibe, es decir las colectividades, incluidas las personas jurídicas. (..) entre las finalidades de esa edidas está el reconocimiento de las víctimas, pero también reafirmar la validez de las normas generales infligidas ( $y$ de esta forma, indirectamente, la importancia de los derechos en general, incluidos, naturalmente los de las víctimas y reafirmando así la condición de estas, o solo como tales victimas sino también como titulares de derecho).

Las reparaciones colectivas no son solo simbólicas; algunas son materiales, como cuando se construye una escuela o un hospital en calidad de reparación, o se destinan a un grupo determinado" (Oficina de Alto Comisionado de las Naciones Unidas para los Derechos Humanos, 2006).

En esta definición de Naciones Unidas, podemos observar tres elementos de la reparación colectiva: los bienes objeto de la reparación, el sujeto beneficiario, y el contenido material y simbólico.

Por otra parte se debe resaltar una importante diferenciación que puede inducir a errores en el momento de identificar cuál es el contenido de la reparación colectiva:

“Existe una gran diferencia entre la reparación de daños colectivos y la reparación colectiva de daños individuales. La primera se fundamenta en el reconocimiento de los efectos que han sufrido las colectividades víctimas, como la destrucción de redes sociales, de propuestas políticas, de cosmovisiones, de alternativas de vida $y$ procesos de construcción de memoria mientras que la segunda, responde a un visión que limita los recursos y mecanismos para la aplicación de una política de reparación integral, en la medida en que homogeniza los daños causados individualmente a los miembros de una comunidad" (Subrayado fuera de texto)(Corporación AVRE, 2008, p.5).

Del análisis de diversos casos de reparación colectiva a nivel internacional (ICTJ, 2009) hemos encontrado que en contextos de pobreza se puede confundir la reparación con programas propios de la justicia social y puede convertirse la reparación colectiva en un herramienta que no pretende otra cosa más que organizar los recursos que suponen escasos para la reparación dirigiéndolos a las víctimas como grupo sin dirigirse a los verdaderos daños sufridos por las colectividades y grupos de allí que:

“Con base en esta aclaración la reparación colectiva, en el marco del derecho a la reparación integral de las víctimas, se orienta hacia el restablecimiento de los derechos vulnerados y a la reparación de los daños ocasionados a las comunidades, grupos $\mathrm{u}$ organizaciones afectadas por hechos de violencia sistemática o selectiva" (Corporación AVRE, 2008, p.5).

Por lo tanto, los bienes objeto de la reparación consistirán en las herramientas propuestas para el restablecimiento de los derechos vulnerados y la reparación de los daños ocasionados; en tanto que el sujeto beneficiario será un sujeto colectivo ya sean comunidades, grupos u organizaciones.

"La noción de víctima está necesariamente vinculada a la definición de violaciones de los derechos humanos o crímenes o conductas reprochables. Para delimitar los contornos de la definición de víctima es necesario preguntarse: ivíctima de qué? La definición de las violaciones de los derechos humanos o de los crímenes que dan lugar a reparación en el marco de un programa administrativo obedec a las particularidades de la represión o la guerra de que se trate, al poder que puedan ejercer distintos actores de la sociedad-incluidos los grupos de víctimas, los propios responsables de las violaciones, a comunidad de derechos humanos y los movimientos feministas, entre otros- $y$ a consideraciones políticas sobre disponibilidad presupuestal” (Díaz, 2009, p.149).

De acuerdo con lo anterior, se deberán aclarar dos elementos a tener en cuenta en la reparación colectiva: quiénes son los sujetos beneficiarios y cuáles son los daños a reparar.
Sujeto a reparar

Con el desarrollo conceptual de los derechos humanos colectivos o de tercera generación, se crea un nuevo sujeto de derechos humanos que viene a superar su percepción individualista, esto es el sujeto cole frente a una violación de sus derechos deberá ser reparado. Sin embargo, aunque se ha avanzado en la definición de los derechos colectivos y en la definición del derecho a la reparación, existen dificultades para vincular estos dos conceptos:

"La definición de víctimas colectivas no parece tan sencilla como la definición de víctimas individuales. La comunidad internacional ha llegado a un amplio consenso en la definición de víctima, que si bien también alude a aquellas personas que hubieren sufrido daños colectivamente, no precisa todos los elementos para definir quiénes son víctimas colectivas" (DÍaz, 2009, p.161).

De allí que se parte de identificar quién es sujeto colectivo para luego definir qué sujetos colectivos son víctimas y por tanto, objeto de reparación colectiva.

"Los sujetos colectivos son aquellos grupos de individuos en los que los fines e intereses van más allá de los de cada uno de los individuos que conforman el sujeto colectivo. Se origina así una voluntad $\mathrm{y}$ un interés que nacen y se sustentan en la voluntad y el interés de los individuos que integran el grupo" (Chacón Belalcázar, 2010, p.11). 
Encontramos aquí dos elementos que defi- se organice con posterioridad aunque sus nen a los sujetos colectivos, la voluntad y el miembros sean los mismos. interés común, que se presenta como dife-

rente de la voluntad a interés de los miem- Por lo tanto, tenemos cuatro elementos que bros de dicho colectivo. Pero más allá de los identifican al sujeto colectivo a efectos de la términos jurídicos, "Las comunidades, las reparación:

organizaciones y los sectores sociales, com- 1 . Identidad común

parten apuestas conjuntas que dan cuenta 2 2. Voluntad común

de proyectos de vida colectivos asociados a 3 3. Intereses comunes

la expresión de intereses compartidos, sobre 4. Preexistencia a la violación.

la base de los cuales se construye identidad y sentido de pertenencia" (Corporación AVRE, p.14).

Por su parte la Corporación AVRE para el caso colombiano presenta cuatro factores a tener en cuenta cuando se trata de identifi-

De allí que se deba recocer la existencia de un proceso identitario al interior del grupo, en el que sus miembros se reconocen como parte del mismo.

"Puede decirse que el sujeto colectivo es un grupo que dispone de "unidad de sentido", diferente de la mera suma de los individuos que conforman el grupo, con un proyecto colectivo identitario. Cuando el sujeto colectivo antecede las violaciones de los derechos humanos de que se trata justamente por su carácter de sujeto colectivo podría pensarse que experimenta daños de naturaleza colectiva" (Subrayado fuera de texto) (Díaz, 2009, p.161).

Además de lo anterior encontramos aqu otro elemento: la preexistencia del grupo a efectos de identificar los daños, dado que la victimización se produce sobre un sujeto colectivo ya existente y la reparación, por tanto, debe dirigirse a ese grupo y no a uno que lesbianas, los bisexuales y los transgeneristas)" (Corporación AVRE, 2008, p.28).

Encontramos en esta propuesta dos elementos: el primero que tiene que ver con el carácter jurídico o no del colectivo, dado que no se necesitaría que el mismo estuviese reconocido como persona jurídica, es el caso de las comunidades campesinas. $Y$ el segundo que vincularía al colectivo a reparar por las condiciones de exclusión y marginación que son la causa de la victimización y que generan un impacto desproporcionado de mismo, como es el caso de las mujeres, la comunidad LGBTI, etc. que debido a patrones culturales estructurales han sufrido la violencia debido a la pretensión de imponer un modelo de sociedad homogeneizado, y que, por tanto, merecen que se visibilicen sus especiales circunstancias y se les repare por dicho daño independientemente que estén constituidos en un grupo.

"Cuando preexiste un sujeto colectivo, puede razonablemente considerárselo como víctima si hubo: violación de derechos colectivos o violación masiva o sistemática de derechos individuales de sus miembros o violación de derechos individuales con graves impactos colectivos, como el asesinato, la desaparición o la tortura de autoridades políticas, administrativas y religiosas tradicionales" (Díaz, 2009, p.161)

Lo que nos deja claro que el concepto de victimas colectivas no solo responde a la masi- vidad de la violación sino a los efectos colectivos del daño causado, como podría suceder en el asesinato de un líder de una comunidad indígena, en el que el ataque se dirige por su condición de tal y con la finalidad de debilitar al grupo, por lo que no solo la víctima directa resulta perjudicada sino todo el grupo al cual pertenecía.

Todos estos elementos nos permiten aproximarnos un poco más a la definición de sujetos colectivos a efectos de la reparación, sin embargo, de cara a un proceso de reparación colectiva, esta definición surge de una decisión política.

\section{Daño colectivo}

Son todas aquellas afectaciones experimentadas por un grupo o comunidad como consecuencia de la violación de derechos humanos de sus miembros con la finalidad de someter o desarticular al grupo.

"Un daño colectivo se genera cuando un hecho de violencia sociopolítica lesiona o pone en riesgo la identidad colectiva y el desarrollo cultural, social y político de una comunidad, organización o sector social.

(...) Es importante reconocer que la valoración de los daños no es universal para todas las personas y colectividades; depende de sus particularidades culturales, étnicas, políticas, generacionales y de género, de la magnitud de los hechos violentos y del contexto en el que ocurren" (Corporación AVRE, 2008, p.13). 
De allí que el daño pone en riesgo los elementos que constituyen el colectivo y que lo definen como tal por lo que su valoración deberá tener en cuenta los elementos diferenciales de cada uno.

De acuerdo con la Corporación AVRE, los tipos de daños colectivos se manifiestan como:

1. Daños a la identidad colectiva

2. Daños a los liderazgos y a la participación

3. Daños a la dignidad y al buen nombre

4. Daños en la identidad cultural y en los elementos simbólicos

5. Ruptura de las dinámicas de relación de los colectivos.

Estos daños generan impactos emocionales y cambios de referentes en los grupos y comunidades victimizadas. Por otra parte existen dos elementos que son consustanciales al daño colectivo: la intencionalidad del mis mo y el contexto de impunidad en que se desarrollan.

“Hay que añadir dos aspectos para valorar y dimensionar los daños colectivos. Por un lado, la intencionalidad de la violencia sociopolítica reflejada en los propósitos de ragmentar los procesos organizativos, generar terror en comunidades para poder ejercer el control, destruir redes, desestimular las propuestas políticas o sociales de la organización, aislar a los miembros, y en los casos más extremos, la desaparición o exterminio de comunidades y organizaciones. Por otro lado, el contexto de mpunidad en que ocurren las violaciones, el cual contribuye a incrementar el dolor, a generar nuevos daños y a intensificar los ya existentes" (Corporación AVRE, 2008, p.13)

Estos elementos sobredimensionan el daño, dado que el primero indica que toda violación colectiva se produce con una finalidad por lo que responden a patrones sistemáticos de violación de derechos humanos y la segunda conduce a la revictimización en contextos en los cuales estos daños no se visibilizan ni se les da respuestas porque se basan en esquemas estructurales del orden político, social y económico de dichas sociedades.

De allí que los daños colectivos tengan causas y finalidades, tal como lo expresa Jiménez Caballero (2010), parafraseando la tesis de Manuel Reyes Mate en La herencia del olvido.

"Someterse a la lógica del progreso, vien a decir, significa aceptar el triunfo definitivo del fascismo. El fascismo es algo más que el fenómeno histórico que llamamos hitlerismo; es una batalla hermenéutica en torno al costo de la historia [...]. El poder del fascismo no consiste tanto en su dominio político planetario cuanto en interiorización de su lógica, es decir, en e consenso alcanzado en nuestra cultura de que el costo es inevitable. (...) por eso sentencia Benjamín, nada ha favorecido tanto al fascismo como la falsa creencia de que es la negación del progreso. Mientras no se vea su relación, la apuesta general a favor del progreso acrecentara el caldo de cultivo de la barbarie" (pp.100 y 101).

\section{Y luego expresa:}

"La tesis de Reyes Mate se puede expresar sintéticamente así: el carácter fascista de la lógica del progreso (que jalona las sociedades contemporáneas) radica en que históricamente han implicado la producció sistemática y masiva de víctimas, tanto como su invisibilización, víctimas que recién ahora han comenzado a ser visibles" (Jiménez Caballero, 2010, pp.100 y 101).

Lo que viene a decir que los procesos de violencia generalizada en los que se producen victimizaciones masivas responden a proyectos de transformación de las sociedades que pretenden imponer nuevos valores y forma de vida aun a costa del supuesto sacrificio de algunos. En este sentido también se pronuncia la Corporación AVRE:

La intencionalidad de los crimenes masivos y sistemáticos en el contexto de violencia sociopolítica es el fortalecimiento de modelos económicos y políticos que aspiran a consolidarse sin tener en cuenta las aspiraciones y necesidades de los diferentes sectores de la sociedad. En el contexto actual del mundo globalizado, son frecuentes las prácticas violatorias $d$ los Derechos Humanos de carácter masivo o sistemático que generan víctimas entre las comunidades y grupos étnicos que habitan territorios ancestrales ricos en recusos naturales, y los sectores sociales que hoy se oponen a los modelos de desarrollo basados en la expansión de las leyes de mercado internacional. Dichas prácticas se desprenden de las alianzas entre instituciones estatales, sectores sociales que detentan el poder político y económico, y empresas multinacionales; alianzas que, anteponiendo sus intereses particulares a los derechos de las colectividades que se resisten frente al modelo que se les quiere imponer, se benefician de las acciones que conducen al aniquilamiento y exterminio de sus opositores.

Los daños colectivos que producen este tipo de prácticas, generalmente son invisibilizados, dando prioridad a las políticas institucionales orientadas a reparar individualmente a las víctimas, por encima de las políticas destinadas a reparar a las colectividades y comunidades victimizadas" (Corporación AVRE, 2008, p.126).

De allí que la exigencia de la reparación colectiva se convierta en un esfuerzo por visibilizar esas prácticas y sus responsables directos e indirectos, por lo tanto en toda definición de daños colectivos se deben observar siempre sus causas e intencionalidad enlazándose aquí con las políticas y programas sobre memoria histórica, de allí la importancia del rescate de la memoria.

Esto amplía el espectro de la reparación coectiva que ya no solo se dirige a los grupos directamente afectados sino que se hace necesaria para la sociedad entera afectada por estos procesos;

"y es que en los casos de graves violaciones de los derechos humanos $y$ violencia 
extrema no solo las víctimas individuales Integralidad del proceso de reparación resultan dañadas, sino que es toda la sociedad quien acaba siendo traumatizada. Es por ello que el proceso de reparaciones no se tiene que enfocar exclusivamente en las víctimas individuales, sino que también se tiene que dirigir al conjunto de la sociedad, que también necesita de un proceso de reparación social" (Gómez Isa 2006, p.35).

En este mismo sentido se pronuncia la Corporación AVRE:

"En contextos de violencia sociopolítica, las violaciones a los Derechos Humanos $y$ los Crímenes de Lesa Humanidad son acontecimientos que tienen efectos colectivos en tanto que perjudican a individuos, comunidades y a la sociedad en general. No obstante, a pesar de su carácter masivo y sistemático, en el tratamiento judicial de estos Crímenes, generalmente se asume cada hecho como "un caso individual", obstaculizando su comprensión como pare de un conjunto de eventos que reproducen patrones de persecución y dinámicas de exterminio, cuya intencionalidad es afectar núcleos humanos determinados" (Corporación AVRE, 2008, p.8).

Por lo tanto, al lado de las reparaciones individuales se debe realizar un proceso de reparación colectiva que busque superar los efectos de la violencia no solo en los grupos sino también en la sociedad misma.
Otro de los elementos a tener en cuenta frente a la reparación colectiva es su integralidad como ya lo vimos la victimización es un proceso complejo que afecta no solo a individuos y grupos específicos sino que daña a la sociedad entera, de allí que la reparación debe construirse en un proceso que encierre diferentes elementos. Gómez Isa propone idea de integralidad externa e interna aś:

"Un proceso de reparaciones tiene que ser integral, tanto en su vertiente externa como interna. A la integralidad externa ya hemos hecho referencia cuando hemos analizado las interconexiones entre verdad, justicia y reparación. Un programa de reparaciones no se debe concebir sin, a mismo tiempo, avanzar en el ejercicio de derecho a la verdad y del derecho a la justicia. La reparación no puede concebirse como un mero sustituto de la verdad $y$ la justicia, como en ocasiones se pretende, ya que ello equivaldría a querer comprar el silencio y la injusticia. Por su parte la integralidad interna hace alusión a que las diferentes medidas de reparación a las víctimas y a la sociedad tienen que ser coherentes y apoyarse mutuamente. La reparación no tiene una dimensión meramente económica, sino que se tiene que abordar como un intento omnicomprensivo de re parar el daño causado a las víctimas y de buscar un nuevo equilibrio político y social, proceso en el que las diferentes me didas de reparación pueden jugar papeles distintos pero complementarios" (Gómez Isa, 2006, p.38).
La integralidad externa tiene que ver, por tanto, con las vinculaciones de la reparación con la verdad y la justicia en el marco de un proceso de justicia transicional, en el que las víctimas no solo se les debe garantizar la reparación sino que se les tiene que garantizar los derechos: a la justicia con la investigación, juzgamiento y sanción de los victimarios directos e indirectos; $y$ a la verdad con identificación de las causas y finalidades de que no solo generaron los hechos victimizantes sino que sustentaron el conflicto.

Por su parte, la integralidad interna responde a las medidas que se deben tomar para satisfacer los anhelos de reparación de cada uno de los colectivos afectados. Estas medidas son las de indemnización, restitución rehabilitación, satisfacción y garantías de no repetición ya estudiadas, pero que se vinculan necesariamente en su contenido con las propuestas de los grupos y comunidades de acuerdo a los daños específicos sufridos por cada una.

“La reparación colectiva se encuentra en estrecha relación con los derechos a la verdad y a la justicia, e implica la adopción de un enfoque diferencial para identificar los daños ocasionados a comunidades sectores sociales, y para adoptar las respectivas medidas de reparación. En este sentido, es necesario elaborar un inventario de daños en cada colectividad víctima teniendo en cuenta sus particularidades étnicas, generacionales, políticas, culturaes $y$ de género, con el fin de establecer una serie de medidas específicas de repa- ración que contemplen las especificidades del grupo afectado y que estén orientadas al reestablecimiento de los derechos vulnerados. Bajo esta perspectiva, la reparación colectiva comprende los componentes de restitución, indemnización, rehabilitación, medidas de satisfacción y garantías de no repetición" (Corporación AVRE, 2008, pp.5 y 6).

\section{Elemento transformador}

La reparación en general y la reparación colectiva en particular, en el marco de un proceso de justicia transicional, no se puede concebir como un momento específico sino que se constituye en un proceso político que busca la transformación de los paradigmas estructurales, sociales, económicos y políticos que dieron origen al periodo de conflicto violencia, para la reconstrucción de la sociedad.

“Nos encontramos ante un proceso político que busca la reconstrucción de la comunidad política, un nuevo equilibrio en la sociedad en el que las víctimas sean reconocidas en su condición de víctimas y pasen a ocupar un nuevo papel en el espacio político y social. En este sentido la reparación pasa a formar parte de un proceso de justicia reparadora y trasformadora, una justicia que lo que pretende, en definitiva, es la plena reparación de las víctimas y la transformación de la sociedad hacia una sociedad más justa en que las víctimas de las violaciones del pasado ocupen su lugar" (Gómez Isa, 2006, p.35). 
DeJuSticia ha propuesto el concepto de "Re- titutorio de las reparaciones podría conducir paración Transformadora" para aplicar a a devolver a las víctimas pobres a situaciones sociedades que han atravesado por un conflicto armado y en las cuales la mayor parte de la población se encuentra en situación de pobreza y exclusión social. Dado que:

“El principio de reparación integral genera paradojas y dilemas difíciles en sociedades que intentan saldar cuentas frente a violaciones graves y masivas a los derechos humanos, ocurridas en regímenes autoritarios o durante conflictos armados. Estas sociedades enfrentan también usualmente profundas desigualdades sociales y económicas y una pobreza extrema muy extendida. (...)

En términos jurídicos, es una tensión entre el deber del Estado de reparar a las víctimas de violaciones graves a los derechos civiles y políticos, debido a crones atroces, el deber del Estado de satisfacer los derechos económicos, sociales y culturales, en especial de poblaciones pobres y vulerables" (Uprimny Yepes, Guzmán Rodriguéz, 2010, pp.236 y 237).

Se identifican entonces dos aspectos: el propósito de estas reparaciones y su alcance. El propósito consiste en que no se debería restaurar a las víctimas a la situación de precariedad previa a la victimización, sino transformar esas situaciones por ser injustas y por haber sido en parte causa de la victimización, y se fundamenta en el hecho de que ciertas sociedades no han alcanzado la justicia distributiva, entonces al aplicar el principio res- El enfoque transformador está implícito en los procesos de reparación colectiva, dado que los conflictos armados y las graves alteraciones del orden público no surgen de la nada, sus causas se fundamentan en unas estructuras políticas y sociales que le dan vida. Por lo tanto, todo proceso de reparación que se precie de ser medianamente justo debe transformar esas realidades para construir una sociedad más justa e igualitaria.

\section{Soluciones normativas propuestas}

De acuerdo con lo estudiado podemos proponer como características y elementos de la reparación colectiva los siguientes:

\section{Caracteristicas externas}

ste grupo de características tiene que ver con el contexto que rodea el proceso de reparación integral y que define su contenido y enfoque:

1. Justicia transicional, observamos cómo el concepto de reparación colectiva, se desarrolla en el marco de estos procesos que se han implementado en algunos países al salir de situaciones de violenci $y$ conflictos armados.

Proceso político, dado que la reparació colectiva se desarrolla en el marco de justicia transicional, nace de una decisión política y se nutre con la participación de diversos actores que hacen presión para que sus consideraciones y aspiraciones de reparación sean tenidas en cuenta. De allí que se deba definir como un proceso, dado que, no se agota en un solo momento sino que se complejiza a medida que se llega a los colectivos y cumple diferentes etapas, así mismo es un proceso político en tanto que se define en el marco de la transformación de las estructuras que le han dado origen al conflicto y por tanto vincula a todos los actores de la sociedad. Será esta dinámica la que le dará contenido material y definirá quiénes serán sus beneficiarios.

3. Integralidad, como lo vimos la reparación colectiva se debe integrar a las otras medidas de reparación propuestas y a los elementos de verdad y justicia en el marco del proceso de transición, dado que estos elementos no se producen aisladamente, sino que se integran como un todo en aras de la satisfacción del derecho de las víctimas y la reconstrucción del proyecto social.

\section{Elementos internos}

Son aquellos que se definen en el proceso de su formulación y que le dan el contenido y alcance a esta forma de reparación, surgen de una decisión política y son básicamente los siguientes:

1. Sujeto, revisamos cuáles son los sujetos que deben ser objeto de este tipo de reparación, de acuerdo con una combinación de criterios pueden tener o no reconocimiento jurídico y pueden o no preexistir al daño, pero comoquiera que sea los colectivos a reparar se definen por su carácter de colectivo, y este carácter surge de un proceso identitario que le da unidad y define una voluntad y una finalidad común. 
2. Daño, son las lesiones que ha sufrido el colectivo en su carácter de tal ya sea por la eliminación de sus miembros o sus figuras más representativas, que se han hecho de manera sistemática, con a finalidad de exterminar o someter a colectivo e imponer patrones de conductas, atacando los elementos que le dan sentido.

3. Objeto, son los elementos que definen el contenido material de la reparación y en términos generales se agrupan en los mismos propuestos para la reparación de acuerdo con el Derecho Internacional, tales son:

Indemnización

Restitución

$>$ Rehabilitación

Satisfacción

Garantías de no repetición.

Estos elementos deberán ser dotados de contenido de acuerdo con la estimación de daño realizada y se deberá tener cuidado de no confundirlos con la política social de Estado de que deben ser beneficiarios todos los ciudadanos, esto con la salvedad de que si la ausencia de dichas medidas sociales permitieron la victimización se deban implementar como una medida para la no repetición de los daños.

\section{Enfoques}

Son los elementos que deben orientar la formulación de los planes de reparación colectiva en todas sus etapas y estar presentes en todas las medidas que se adopten de manera transversal:

1. Transformador, este enfoque se orienta hacia la transformación de todas las realidades políticas, económicas y sociales que permitieron o fueron causa de victimización y de los patrones culturale que generaron una especial afectación en grupos poblacionales tradicionalmente excluidos y marginados y que generaron un impacto desproporcionado de la violencia en los mismos.

2. Participativo, el contenido de la reparación colectiva en todos sus elementos se debe definir con la consulta y participación de las víctimas en todas las etapas del proceso, será este el elemento que le dará legitimidad, dado que no se pueden definir al marguen de las particularidades y el sentir de cada uno de los colectivos victimizados. En este se deberá dar herramientas para la participación de la población que haciendo parte de estos colectivos cuente con criterios que dentro del grupo social sean objeto de discriminación y exclusión

3. Diferencial, deberá surgir el contenido de la reparación colectiva de la valoración de los daños causados a los colectivos afectados que dadas las particula ridades de cada uno habrán respondido a patrones distintos, por lo que la reparación también deberá responder a esas particularidades, además de las diferencias entre un colectivo $u$ otro a efectos de la reparación se deberán tener en cuenta las diferencias que dentro del mismo colectivo presentan algunos de su miem- bros, tales como mujeres, niños, niñas y se produce la necesidad debido a la magniadolescentes, discapacitados, ancianos, tud de los daños experimentados de estaLGBTI, etc.

\section{CONCLUSIONES}

La justicia transicional es el marco contextua en el que se desarrolla el concepto de reparación colectiva y se presenta en dos dimensiones: una de carácter judicial que privilegia la investigación de los hechos ocurridos la imputación de responsabilidades a los perpetradores y una dimensión política que integra una serie de procesos que conducen a la transformación social e institucion de los Estados. En este proceso los diferen tes gobiernos implementan medidas tales como: Comisiones de la Verdad, Programas de reparación, acciones penales y diferentes reformas institucionales, que pretenden satisfacción de los derechos a la verdad, la justicia, la reparación y las garantías de no repetición.

Por lo tanto, la justicia transicional se conforma como un proceso jurídico y político en el que el que se pretende lograr a través de diversos mecanismos e instrumentos excepcionales, la transformación de las estructuras sociopolíticas que fueron causa de conflictos y tensiones y que se presenta como respuesta a las graves, masivas y sistemáticas violaciones de derechos humanos para la que los procesos y normas ordinarias tanto nacionales como internacionales no tienen respuestas adecuadas.

Es en el marco de estos procesos en donde blecer mecanismos que tiendan a satisfacer los derechos a la indemnización, restitución, rehabilitación, satisfacción, y garantías de no repetición para los grupos, comunidades y la sociedad misma que se han visto afectados como consecuencia de la magnitud y masificación de las violaciones; esto es desarrollar herramientas para las reparaciones colecti-

Cuando hablamos de reparación colectiva, hablamos de realidades que desbordan los estándares tradicionales del derecho a la reparación: ante la alegada imposibilidad de los Estados de reparar individualmente a grandes números de personas y la necesidad de visibilizar el impacto en los grupos y en la sociedad de periodos de violencia, de allí que la idea de reparación colectiva se presente como necesaria en el marco de lo que se entiende como justicia transicional.

Del análisis de algunos de los casos de países que han establecido procesos de justicia transicional y en los que se han recomendado medidas de reparación colectivas, encontramos que esta es presentada y utilizada como una herramienta que gira en torno a dos ideas:

1. Permite homogeneizar las medidas de reparación individual para evitar los costos de una reparación integral a las víctimas.

Su contenido es presentado como medida de asistencia social, y se aprovechan 
de la situación de marginación tradicional de las comunidades victimizadas para entregar esta medida como reparación.

Sin embargo, la reparación colectiva no puede ser utilizada para salvar la responsabilidad del Estado de reparar, de allí que la definición de su contenido y elementos permite crear una herramienta para la exigibilidad de ese derecho en toda su plenitud.

\section{REFERENCIAS}

Beristan, C. M. (2010). Diálogos sobre la reparación: Qué reparar en los casos de violaciones de derechos humanos. San José, Costa Rica: Instituto Interamericano de Derechos Humanos.

Bonet Pérez, J. \& Alija Fernández, R. A. (2009). Impunidad, derechos humanos y justicia transicional. Cuadernos Deusto de Dere chos Humanos, No. 53. Bilbao: Universidad Deusto.

Brito Ruiz, D. (2010). Justicia Restaurativa reflexiones sobre la experiencia de Colombia. Ecuador: Universidad Técnica Particular de Loja. Colección Cultura de Paz.

Centro Internacional para la Justicia Transicional (ICTJ) (2009). ¿Qué es justicia transicional? Disponivel em:<http://icti.org/sites/ default/files/ICTJ-Global-Transitional-Justice-2009-Spanish.pdf>. Acesso em 1 de Setembro de 2012
Chacón Belalcázar, Á A. (2010). Alcances de la Reparación Colectiva. Colombia: Defensoría del Pueblo.

Corporación AVRE (octubre de 2008). Dimensión política de la reparación colectiva. Voces de memoria y dignidad/Cuaderno de Reflexión sobre Reparación Integral.

Díaz, C. (2009). La Reparación Colectiva: Problemas conceptuales en perspectiva comparada. Reparar en Colombia: Los dilemas en contextos de conflicto, violencia y exclusión.

Estatuto de Roma de la Corte Penal Internacional. Aprobado el 17 de julio de 1998 por la Conferencia Diplomática de Plenipotenciarios de las Naciones Unidas sobre el establecimiento de una Corte Penal Internacional. Distr. General A/CONF.183/9. Entró en vigor el 10 de julio de 2002.

Gómez Isa, F. (2006). El derecho a la memoria. Alberdania.

ICTJ. Informe de Rabat. Disponível em <http://ictj.org/sites/default/files/ICTJ-Morocco-Reparations-Report-2009-Spanish. pdf $>$. Acesso em 12 de agosto de 2014

Jiménez Caballero, C. (2010). El campo psicosocial, conceptos e implicaciones en tareas pendientes: propuesta para la formulación de políticas públicas de reparación en Coombia. Bogotá: Centro Internacional para la Justicia Transicional (ICTJ).
Oficina del Alto Comisionado de las Naciones Uprimny Yepes, R. \& Guzmán Rodríguez, Unidas para los Derechos Humanos (2006). D. E. (2010). En búsqueda de un concepto Instrumentos del estado de derecho para transformador y participativo para las resociedades que han salido de un conflicto, paraciones en contextos transicionales. 17 iniciativas de enjuiciamiento. New York: Gi- International Law, Revista Colombiana de

Derecho Internacional. Colombia: Pontificia Universidad Javeriana. 